\title{
Physical and Barrier Properties of Clove Essential Oil Loaded Potato Starch Edible Films
}

\author{
Stoil Zhelyazkov ${ }^{\text {(D) }}$, Gabor Zsivanovits ${ }^{1, *(D)}$, Eleonora Stamenova ${ }^{1}$, Maria Marudova ${ }^{2}$ (D) \\ 1 Institute of Food Preservation and Quality, 153 Vasil Aprilov Blvd., 4003 Plovdiv; s.zhelyazkov@canri.org (S.Z.); \\ g.zsivanovits@canri.org (G.Z.); elistamenova@abv.bg (E.S.); \\ 2 University of Plovdiv "Paisii Hilendarski", Department of Physics and Technology, 24 Tzar Assen str., 4000 Plovdiv, \\ Bulgaria; marudova@uni-plovdiv.net (M.M.); \\ * Correspondence: g.zsivanovits@canri.org (G.Z.);
}

Scopus Author ID 55309673700

Received: 10.08.2021; Revised: 20.09.2021; Accepted: 24.09.2021; Published: 16.10.2021

\begin{abstract}
This study explores the effect of Clove essential oil (CEO) nanoemulsion on the physical and physicochemical properties of potato starch edible films. Mechanical properties at puncture tests, film thermal stability, morphology, color CIELAB parameters, water vapor permeability, and gas barrier properties towards oxygen and carbon dioxide were determined. Films were characterized with white color and high opacity. The films' surface morphology was examined by polarized microscopy, and homogeneous distribution of the incorporated nanoemulsion into the edible film was observed. The loaded CEO improved the water and gas barrier properties of the films. In this way, the formulated new multicomponent films are suitable for use in the design of active food packaging.
\end{abstract}

Keywords: multicomponent edible films; starch; clove essential oil; thermal stability; film morphology; permeability properties; color properties; puncture tests.

(C) 2021 by the authors. This article is an open-access article distributed under the terms and conditions of the Creative Commons Attribution (CC BY) license (https://creativecommons.org/licenses/by/4.0/).

\section{Introduction}

In recent years, a tendency to replace synthetic polyolefin packaging with environmentally friendly, edible, and biodegradable films using natural resources has been observed. The basic materials, which have been used in the formulation of edible film, are polysaccharides, proteins, and lipids [1]. All of them are safe and permitted for food purposes. They possess good barrier properties and can significantly decrease undesired interactions between the food surface and the external environment [2]. One of the advantages of edible packaging is including various biologically active substances, such as coloring agents, antimicrobial agents, and antioxidants [3].

Starch is a polysaccharide, which is commonly used for packaging applications because it is cheap and possesses some of the preferable properties of edible coatings - it is tasteless, odorless, flexible, and transparent [4]. Starch films have excellent gas barrier properties and retarded aroma and solutes transfer [5]. The main disadvantage of the starch-based edible films is their strong affinity for water [6]. To reduce the water vapor permeability of the films, different hydrophobic ingredients, like lipids, waxes, or essential oils, are incorporated into the packaging material $[7,8]$.

The present research describes clove essential oil-loaded starch films' physicomechanical, barrier, structural, thermal, and optical properties. 


\section{Materials and Methods}

\subsection{Materials.}

Potato starch and Tween 20 were purchased from SIGMA Aldrich, Germany. Clove essential oil (CEO) and plasticizer (glycerol) were provided from the local market.

\subsection{Preparation of Clove essential oil nanoemulsion.}

The nanoemulsion was formulated using $10 \% \mathrm{w} / \mathrm{w}$ Clove essential oil (CEO), $10 \%$ w/w Tween 20 , and $80 \%$ w/w distilled water. The compounds were vortexed with PV-1 Vortex Mixer (Grant Instruments, UK) at room temperature for $5 \mathrm{~min}$. Then the obtained emulsion was ultrasonicated for 3 min using UP100H - Compact Ultrasonic Laboratory Device, Germany.

\subsection{Formulation of edible films from potato starch with incorporated CEO.}

The method of Alaa G. Al-Hashimi [3] with a few modifications was used to prepare the edible films. Briefly, potato starch $(3 \% \mathrm{w} / \mathrm{w})$ was dissolved in distilled water. The starch was gelatinized at $85{ }^{\circ} \mathrm{C}$ using a continuous heated magnetic stirrer, after which the solution was cooled down to room temperature. $1 \%$ plasticizer (glycerol) was added to the starch solution at $60{ }^{\circ} \mathrm{C}$ and homogenized with a magnetic stirrer for $30 \mathrm{~min}$. After the homogenization, the mixture was cooled down again to room temperature. Then the Clove essential oil nanoemulsion was poured under constant stirring to the starch solution at a proper amount to reach $0.5 \%, 1.0 \%, 1.5 \%, 2.0 \%$ and $2.5 \%$ concentrations. The films were prepared by casting method using approximately $40 \mathrm{ml}$ of the starch solution into Petri dish $(\varnothing=100$ $\mathrm{mm})$. The Petri dishes were covered with aluminum foil and dried at $30{ }^{\circ} \mathrm{C}$ for 7 days.

\subsection{Polarizing light microscope.}

A polarizing light microscope (Leica DM1000) equipped with Leica DFC295 Digital Camera was used to observe the morphologies of the films.

\subsection{Film thickness.}

The thickness was measured in ten repetitions randomly on each testing sample with a digital micrometer (No. 293-5, Mitutoyo, Japan). The average values were used to calculate the gas and water vapor permeability.

\subsection{Determination of moisture content of the potato starch edible films.}

Sartorius moisture analyzer was used for measuring the equilibrium moisture content of the edible films. Five replications were done for each sample.

\subsection{Determination of the potato starch edible films solubility.}

Cut film pieces $(2 \times 2 \mathrm{~cm})$ were immersed in distilled water at room temperature for 6 hours. Then, the film pieces were taken out and dried at $105{ }^{\circ} \mathrm{C}$ for $60 \mathrm{~min}$ and weighted to calculate the solubility $(\%)$. 
2.8. Water vapor permeability (WVP).

The gravimetric method was used to measure the water vapor permeability and water vapor transmission rate by W3/031 (Labthink, China) instrument. The generated humidity difference was $90 \%$ between the two sides of the test film.

\subsection{Oxygen and carbon dioxide permeabilities.}

ASTM D1434 standard (2015) was applied for determining the oxygen $\left(\mathrm{O}_{2}\right)$ and carbon dioxide $\left(\mathrm{CO}_{2}\right)$ permeability of the studied films. Samples were examined by VAC-VBS Gas Permeability Tester, Labthink, China.

\subsection{Mechanical penetration tests.}

The slow-speed puncture test of the films was done based on the standard tests, with some modifications. A TA.XT2 Texture Analyser (Stable Micro Systems, Surrey, UK) was used for the measurements. The $40 \mathrm{~mm}$ diameter stretched film discs were punctured by a 5 $\mathrm{mm}$ spherical probe. Five pieces of films were measured from each concentration. The deformation speed was $1 \mathrm{~mm} / \mathrm{s}$ until the film broke. The force at break (FB $[\mathrm{N}]$ ), the deformation at break $(\ell[\mathrm{mm}])$, the elastic modulus (force/linear deformation, $\lambda[\mathrm{N} / \mathrm{mm}]$ ) and the deformation work $\left(\int_{0}^{F_{R}} F d \ell[\mathrm{N} . \mathrm{mm}]\right)$ were statistically analyzed.

\subsection{Determination of color parameters of the potato starch-based films.}

The color properties of the films were examined by a portable colorimeter PCE-CSM 5. The CIELAB color coordinates L, a, b, c, and h were measured (Measuring geometry $8 \%$, $\varnothing 8 \mathrm{~mm}$, light source D65), and ISO whiteness and yellowness indexes were calculated by the Color Quality Controller System 3 software. The instrument was calibrated by a white etalon $\left(L^{*}=94.3 ; a^{*}=-0.92 ; b^{*}=-0.67\right)$. The same white etalon was applied to the background of the experiments [9]. All films were measured at 5 places.

\subsection{Thermal analysis.}

Differential scanning calorimetry was applied for the investigation of the thermal properties and stability of the edible films. DSC 204F1 Phoenix (Netzsch Gerätebau GmbH, Germany) was used in this study. The temperature and the heat flow calibration were performed by indium standard $\left(\mathrm{T}_{\mathrm{m}}=156.6^{\circ} \mathrm{C}, \Delta \mathrm{H}_{\mathrm{m}}=28.5 \mathrm{~J} / \mathrm{g}\right)$. Samples from the edible films (about 15 $\mathrm{mg}$ ) were hermetically sealed in aluminum pans. An identical empty pan was used as a reference. The measurements were performed under argon atmosphere at a heating rate of 10 ${ }^{\circ} \mathrm{C} / \mathrm{min}$.

\section{Results and Discussion}

\subsection{Potato starch-based films morphology.}

The surface morphology of the control and CEO-loaded films was investigated by polarized microscopy - Figure 1 .

The film without CEO is characterized by a flat and homogenous surface (Figure 1). The CEO loading to the films lowered the uniformity of the films as the process did not depend on the oil concentration (Figure 1) and introduced a diphasic structure consisting of 
hydrophobic CEO droplets suspended in a hydrophilic polymer matrix. A uniform distribution of the CEO in the starch matrix was observed for all samples. The droplet concentration and size increased with increasing the CEO concentration.
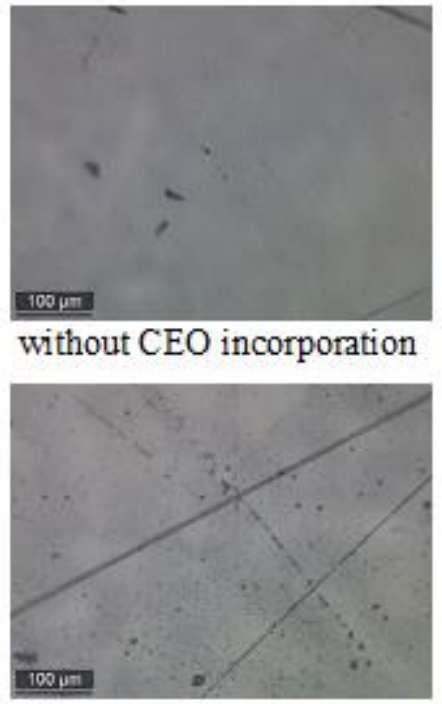

with $1.5 \% \mathrm{CEO}$

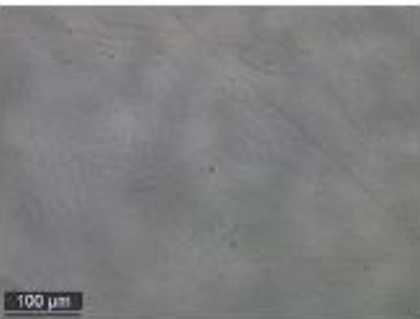

with $0.5 \% \mathrm{CEO}$

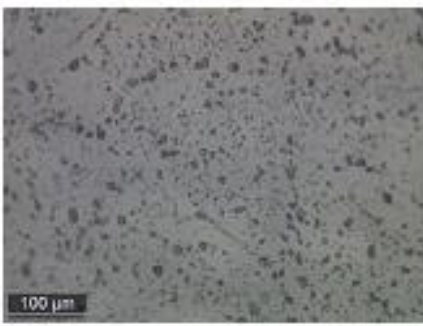

with $2.0 \% \mathrm{CEO}$

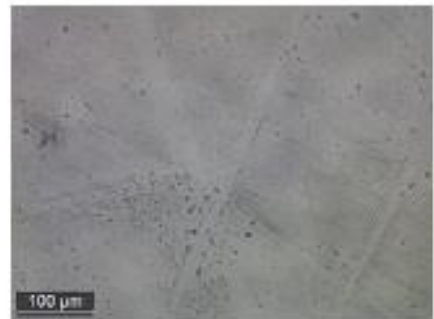

with $1.0 \% \mathrm{CEO}$

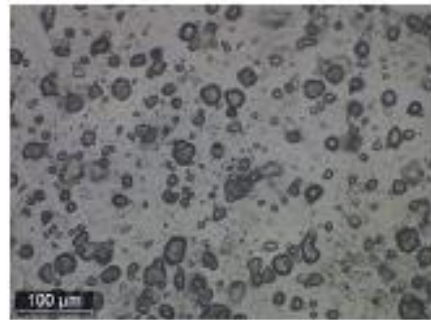

with $2.5 \% \mathrm{CEO}$

Figure 1. Morphology of potato starch films.

\subsection{Potato starch-based films thickness and water affinity.}

One of the significant parameters of the films is their thickness, which directly determines the gas and water vapor permeation, color, and mechanical properties. Therefore, this parameter can influence the packaged food product's shelf life.

The thickness of the films varied between $(0.119 \pm 0.009) \mathrm{mm}$ and $(0.221 \pm 0.006) \mathrm{mm}$ (Table 1). The thickness of the control sample is the smallest. The thickness of the films with CEO increases significantly $(p<0.05)$ when the amount of the oil increases. This phenomenon could be associated with the inclusion of CEO droplets within film bulk, which change material density and the amount of the dry compounds since the same volume of solution was poured at each Petri dish. In this way, the amount of total solids of the film increased after the drying process. The received results are in agreement with the reports of other authors [10].

The moisture content of all investigated samples is shown in Table 1. The CEO loading into the films lowered the moisture content regardless of the oil concentration.

Table 1. Effect of clove essential oil concentration on physical parameters of potato starch films.

\begin{tabular}{c|c|c|r|r} 
Formulation & Thickness $(\mathbf{m m})$ & $\begin{array}{c}\text { Moisture content } \\
(\boldsymbol{\%})\end{array}$ & Solubility in water $(\boldsymbol{\%})$ & $\begin{array}{c}\text { WVP } \\
\text { (g.mm/m2.day.kPa) }\end{array}$ \\
\hline Control & $0.119 \pm 0.009 \mathrm{a}$ & $8.03 \pm 0.33 \mathrm{c}$ & $31.01 \pm 0.017$ & $7.70 \pm 0.33$ \\
\hline CEO 0.5\% & $0.139 \pm 0.009 \mathrm{~b}$ & $6.49 \pm 0.26 \mathrm{a}$ & $34.84 \pm 0.017$ & $5.23 \pm 0.31$ \\
\hline CEO 1.0\% & $0.149 \pm 0.007 \mathrm{c}$ & $7.02 \pm 0.28 \mathrm{~b}$ & $35.21 \pm 0.015$ & $4.50 \pm 0.25$ \\
\hline CEO 1.5\% & $0.155 \pm 0.017 \mathrm{c}$ & $6.22 \pm 0.24 \mathrm{a}$ & $35.48 \pm 0.016$ & $4.17 \pm 0.17$ \\
\hline CEO 2.0\% & $0.166 \pm 0.014 \mathrm{~d}$ & $6.61 \pm 0.26 \mathrm{a}$ & $36.07 \pm 0.018$ & $4.00 \pm 0.17$ \\
\hline CEO 2.5\% & $0.221 \pm 0.006 \mathrm{e}$ & $7.02 \pm 0.27 \mathrm{~b}$ & $38.86 \pm 0.018$ & $3.77 \pm 0.26$
\end{tabular}

Unlike glycerol, which absorbs the maximum amount of moisture without any obstacles, the essential oil, due to its hydrophobic nature, prevents the high absorption of moisture. The presence of fatty acids in the essential oil causes interaction with the active starch groups, which hinders the formation of hydrogen bonds between water molecules and active starch groups [11]. 
Solubility in water for edible films is a highly important parameter in wet environments due to water resistance. It determines the protecting properties of coating with high water activity like fresh and frozen food [12].

The films with CEO, showed higher solubility (Table 1) than the control films. The solubility increased with increasing the CEO concentration. At first glance, this result is unexpected, as the addition of a hydrophobic component is expected to reduce solubility values [13]. The solubility increasing is due to film defects, which favor the water inclusion to the polymer matrix and raise the thickness and rough surface structures of the films, raising the film and water contact area [14].

The high water-solubility is favorable in applying the films for coating of fruits and vegetables due to later washability of it [15] according to consumer preferences.

WVP is a highly important parameter in the characterization of the edible coating materials' quality.

One of the essential functions of edible coatings is to reduce the transport of water between food and its environment or between the separated components of food, which should have minimal water vapor permeability. [16].

The control film had the highest water vapor permeability with a value of $(7.70 \pm 0.33)$ g. $\mathrm{mm} / \mathrm{m}^{2}$.day. $\mathrm{kPa}$ - table 1. Other films had a significant difference $(\mathrm{p}<0.05)$, and the WVP of films decreased with increasing the amount of CEO in the films. The lowest WVP is related to the sample with $2.5 \% \mathrm{CEO}-(3.77 \pm 0.26) \mathrm{g} . \mathrm{mm} / \mathrm{m}^{2}$.day.kPa.

There are various data in the literature on the influence of the incorporated essential oil on the vapor permeability of edible films. In some cases, the authors report increased WVP when essential oils are incorporated $[14,17,18]$. The increasing of films WVP was influenced by the generation of the holes that caused structural changes in the polymer network and forwarded the water vapor transfer.

The decrease of the WVP in the present research could be attributed to two reasons. First, glycerol, acting as a plasticizer, decreases the intermolecular hydrogen bonds and increases the free volume between starch molecules. In this way, facilitates the diffusion of the water vapor molecules through the film. Second, the newly created hydrogen bindings between starch network and CEO compete the hydrophilic relationship between hydrogen group and water, and in this way lowering the film's water affinity [10].

\subsection{Potato starch films gas permeability.}

There is a significant increase in the permeability of both gases - $\mathrm{O}_{2}$ and $\mathrm{CO}_{2}$, compared to the control film - Figure 2. An important factor for barrier efficiency is the impact of lipid integration on the microstructure of the coating films. The molecular mobility is enhanced by the liquid state of the CEO, which assists the transfer of gas molecules. In addition, the hydrophobic nature of the CEO causes it to interact with the polymer matrix and disrupt the hydrogen bonds [19]. In this way, additional sites for the dissolution of gases may be created, and the mobility of molecules can be increased through film structure.

\subsection{Puncture properties.}

The puncture properties of edible films are highly important for processing requirements [20]. Puncture characteristics of the films and coatings are influenced by the 
interactions of additive matrix and are highly determined by the environment, which controls the stability and flexibility of the film.

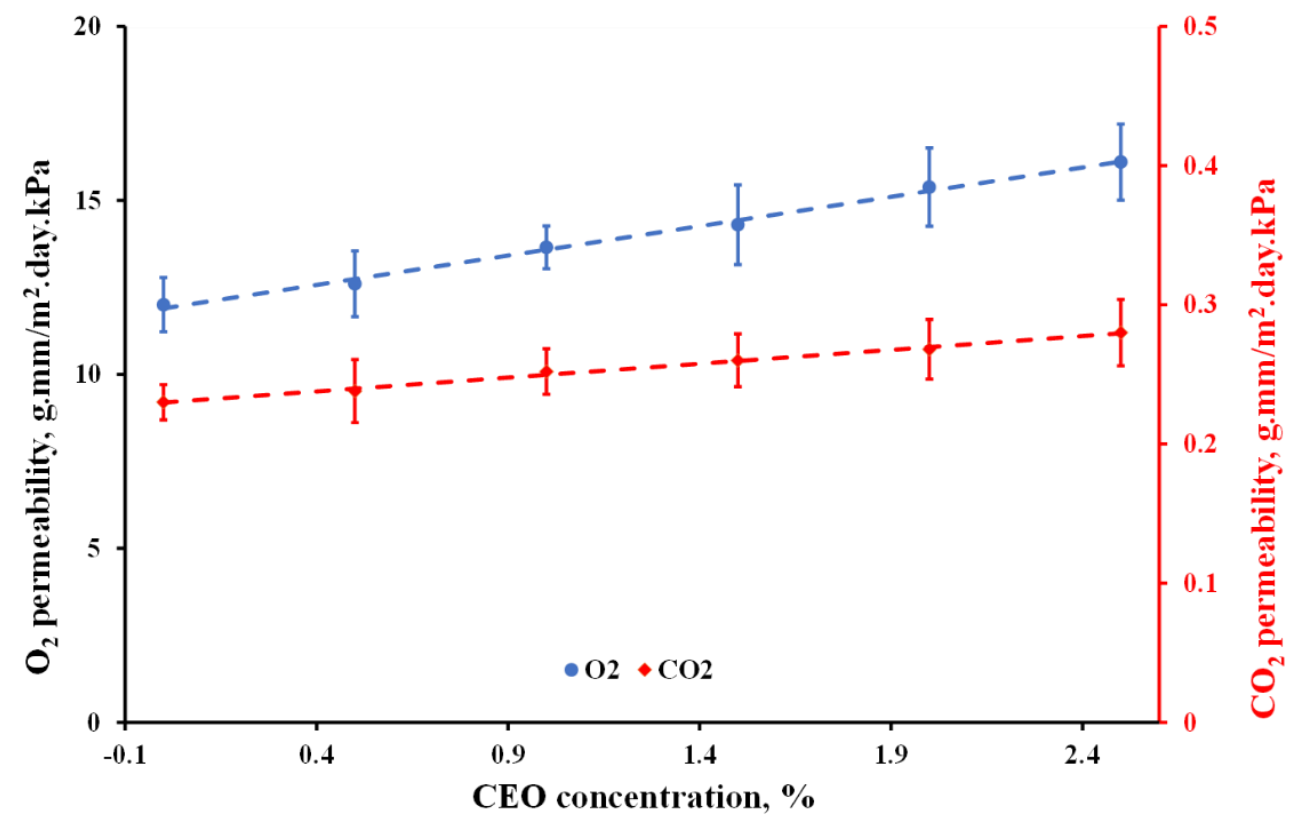

Figure 2. Gas permeability of potato starch films containing different concentrations of Clove essential oil (CEO).

The elastic parameters of the examined films are presented in Table 2. Based on our results, a significant difference was found in rupture force $(\mathrm{p}<0.05)$.

Table 2. Elastic properties of potato starch films containing different concentrations of Clove essential oil (CEO).

\begin{tabular}{c|r|r|r|r} 
Formulation & Rupture force (N) & Rupture distance $(\mathbf{m m})$ & $\begin{array}{c}\text { Rupture work } \\
\mathbf{( N . m )}\end{array}$ & Deformation modulus (N/m) \\
\hline Control & $23.039 \pm 3.123 \mathrm{a}$ & $3.421 \pm 0.446 \mathrm{a}$ & $36.702 \pm 6.330 \mathrm{a}$ & $9.287 \pm 0.912 \mathrm{a}$ \\
\hline CEO 0.5\% & $22.900 \pm 3.635 \mathrm{a}$ & $3.368 \pm 0.234 \mathrm{a}$ & $34.387 \pm 5.074 \mathrm{a}$ & $9.019 \pm 0.916 \mathrm{a}$ \\
\hline CEO 1.0\% & $14.059 \pm 1.335 \mathrm{~b}$ & $3.419 \pm 0.274 \mathrm{a}$ & $20.374 \pm 2.389 \mathrm{~b}$ & $8.664 \pm 0.981 \mathrm{a}$ \\
\hline CEO 1.5\% & $16.304 \pm 3.085 \mathrm{~b}$ & $2.707 \pm 0.186 \mathrm{~b}$ & $20.640 \pm 3.138 \mathrm{~b}$ & $5.168 \pm 0.586 \mathrm{~b}$ \\
\hline CEO 2.0\% & $5.577 \pm 0.360 \mathrm{c}$ & $2.504 \pm 0.270 \mathrm{~b}$ & $11.397 \pm 1.645 \mathrm{c}$ & $3.329 \pm 0.354 \mathrm{c}$ \\
\hline CEO 2.5\% & $4.481 \pm 0.378 \mathrm{c}$ & $1.588 \pm 0.252 \mathrm{c}$ & $5.465 \pm 0.572 \mathrm{~d}$ & $2.409 \pm 0.364 \mathrm{c}$
\end{tabular}

Thus, the control sample had the highest rupture force $(23.039 \mathrm{~N})$, and the sample with $2.5 \% \mathrm{CEO}$ had the least resistance to stretching (4.481 N). In the investigated systems, due to the plasticizing effect of the essential oil, the intra- and intermediate molecular hydrogen bonds between the amylose and the amylopectin chain are partially destroyed, and the film strength decreases. As a result, the molecular movement and the polymer's flexibility increase [21].

The maximum value for the rupture distance is observed for the control sample (3.421 $\mathrm{mm}$. The lowest value of the rupture distance with a significant difference from the other samples is for the film with $2.5 \%$ CEO $(1.588 \mathrm{~mm})$.

The limited interactions between the polymer chains provoke a decrease in the elasticity resistance (rupture work) and deformation modulus and increase in the elasticity. Similar results were received for the mechanical characteristics of edible starch films loaded with essential oil, which were studied by tensile test [22].

\subsection{Color properties.}

The main function of formulating starch films is to prevent the packaged product's taste, color, flavor, and appearance changes [23]. Table 3 shows the colorimetric parameters of the films. 
Table 3. Colorimetric parameters of potato starch films containing different concentrations of Clove essential oil (CEO).

\begin{tabular}{c|c|c|c|c|c|c|c} 
Formulation & $\mathbf{L}^{*}$ & $\mathbf{a}^{*}$ & $\mathbf{b}$ & $\mathbf{\mathbf { c } ^ { * }}$ & $\mathbf{h}$ & $\mathbf{W I}$ & $\mathbf{Y I}$ \\
\hline Control & $93.12 \pm 0.19 \mathrm{a}$ & $-0.99 \pm 0.07 \mathrm{a}$ & $-0.89 \pm 0.12 \mathrm{a}$ & $1.31 \pm 0.13 \mathrm{~B}$ & $221.86 \pm 2.96 \mathrm{a}$ & $84.99 \pm 0.28 \mathrm{a}$ & $-2.26 \pm 0.29 \mathrm{a}$ \\
\hline CEO 0.5\% & $92.51 \pm 0.42 \mathrm{a}$ & $-0.90 \pm 0.01 \mathrm{~b}$ & $-0.34 \pm 0.01 \mathrm{ab}$ & $0.96 \pm 0.02 \mathrm{AB}$ & $200.45 \pm 0.47 \mathrm{~b}$ & $82.87 \pm 0.94 \mathrm{~b}$ & $-1.09 \pm 0.03 \mathrm{ab}$ \\
\hline CEO 1.0\% & $92.38 \pm 0.34 \mathrm{a}$ & $-0.88 \pm 0.01 \mathrm{~b}$ & $0.39 \pm 0.05 \mathrm{~b}$ & $0.96 \pm 0.04 \mathrm{AB}$ & $156.16 \pm 2.65 \mathrm{c}$ & $82.07 \pm 0.32 \mathrm{c}$ & $0.36 \pm 0.10 \mathrm{~b}$ \\
\hline CEO 1.5\% & $92.52 \pm 0.04 \mathrm{a}$ & $-0.86 \pm 0.05 \mathrm{~b}$ & $0.45 \pm 0.03 \mathrm{~b}$ & $0.94 \pm 0.02 \mathrm{~A}$ & $151.61 \pm 1.73 \mathrm{~d}$ & $81.64 \pm 0.79 \mathrm{c}$ & $0.53 \pm 0.06 \mathrm{~b}$ \\
\hline CEO 2.0\% & $89.42 \pm 0.30 \mathrm{~b}$ & $-0.19 \pm 0.01 \mathrm{c}$ & $3.45 \pm 0.11 \mathrm{c}$ & $3.46 \pm 0.11 \mathrm{C}$ & $92.63 \pm 0.99 \mathrm{e}$ & $71.51 \pm 0.48 \mathrm{~cd}$ & $7.06 \pm 0.19 \mathrm{c}$ \\
\hline CEO 2.5\% & $86.78 \pm 1.01 \mathrm{c}$ & $0.37 \pm 0.03 \mathrm{~d}$ & $6.53 \pm 1.47 \mathrm{~d}$ & $7.22 \pm 0.51 \mathrm{D}$ & $86.57 \pm 2.80 \mathrm{f}$ & $62.90 \pm 3.46 \mathrm{~d}$ & $13.81 \pm 3.29 \mathrm{~d}$
\end{tabular}

The control film was almost colorless. The potato starch is light color material, and the developed film is translucent [24]; the values of color parameters were close to the values of the white etalon plate, which was used as a background. Due to the dyeing effect of the COE, by adding CEO in a different amount to the films, their color changed. The CEO reduced the whiteness and increased the yellowness values. Similar data were reported for HPMC edible films with incorporated CEO [25].

\subsection{Thermal properties and stability of potato starch edible films.}

Thermal properties and the stability of the potato starch edible films were characterized by DSC - Figure 3.

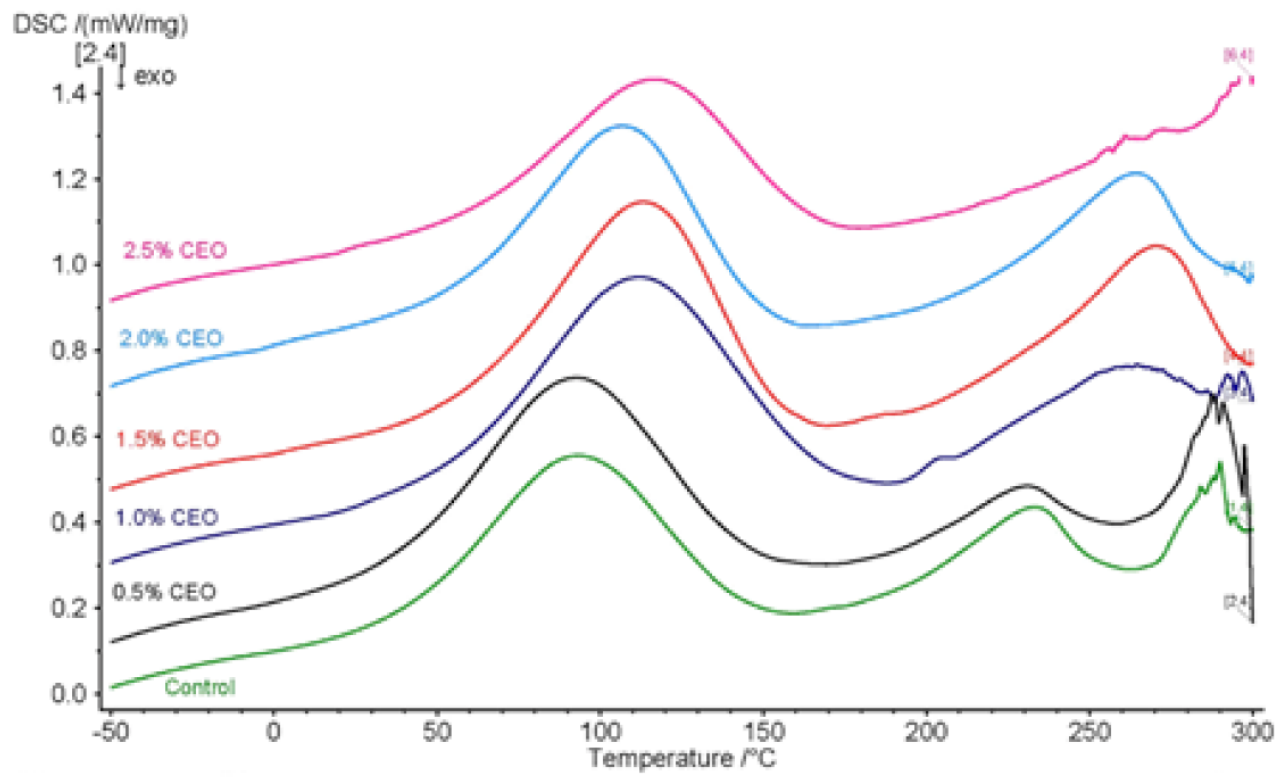

Figure 3. DSC thermograms of potato starch films containing different concentrations of Clove essential oil (CEO).

Table 4. DSC thermograms of potato starch films containing different concentrations of Clove essential oil

\begin{tabular}{c|c|c|c}
\multicolumn{3}{|c}{$(\mathrm{CEO})}$. \\
Formulation & $\mathbf{T}_{\mathbf{o n}}\left({ }^{\circ} \mathbf{C}\right)$ & $\mathbf{T}_{\mathbf{m}}\left({ }^{\circ} \mathbf{C}\right)$ & $\Delta \mathbf{H}_{\mathbf{m}}(\mathbf{J} / \mathbf{g})$ \\
\hline Control & 43.4 & 92.4 & 157.0 \\
\hline CEO 0.5\% & 42.1 & 92.3 & 189.3 \\
\hline CEO $1.0 \%$ & 59.3 & 111.9 & 223.3 \\
\hline CEO $1.5 \%$ & 59.3 & 112.9 & 212.8 \\
\hline CEO $2.0 \%$ & 56.2 & 106.7 & 181.7 \\
\hline CEO $2.5 \%$ & 63.5 & 115.9 & 155.3
\end{tabular}

The obtained thermograms presented one predominating broad endothermal peak in the temperature range between $20{ }^{\circ} \mathrm{C}$ and $190{ }^{\circ} \mathrm{C}$. Most likely, it is due to two processes: incomplete starch gelatinization during film preparation and water evaporation [26]. A second endothermal phenomenon is realized at temperatures above $170^{\circ} \mathrm{C}$, which could be related to 
the thermal destruction of the film [27]. Incorporating a different amount of essential oil led to a shift of the peak's temperatures and a change in the enthalpy of the endothermic process (Table 4).

At CEO concentration up to $1.0 \%$, there is a trend in the values of $\Delta \mathrm{H}_{\mathrm{m}}, \mathrm{T}_{\mathrm{on}}$, and $\mathrm{T}_{\mathrm{m}}$ to increase. Therefore, the hydrogen bonding interaction between the starch network and CEO may hinder the processes of gelatinization and water evaporation and stabilize the film. At higher levels of CEO, the values of $\Delta \mathrm{H}_{\mathrm{m}}, \mathrm{T}_{\mathrm{on}}$, and $\mathrm{T}_{\mathrm{m}}$ tend to decrease. In this case, it could be assumed that the incorporated to the edible films essential oils act as a plasticizer, i.e., it facilitates chain mobility [28], and the films become thermally less stable.

\section{Conclusions}

The physicochemical properties of casted potato starch films, with incorporated different concentrations of Clove essential oil (CEO) $(0.5 \%, 1.0 \%, 1.5 \%, 2 \%$, and $2.5 \%$ ) were investigated in the present research. With the CEO loading to the films, the film's thickness increased, which affected the opacity of the films and increased the film turbidity and yellowness. The increase in the concentration of the incorporated essential oil led to a decrease in the moisture content and the WVP of the films. These improved the water resistance of the starch films and made them desirable for food packaging. The addition of essential oil caused a significant lowering in the rupture force and rupture distance of the films compared to the control sample. Based on the thermal analysis, the incorporation of CEO up to $1 \%$ stabilized the films. The prepared multicomponent films with improved physical properties could be a promising material for fabricating functional food packaging.

\section{Funding}

This research was funded by Bulgarian National Science Fund (BNSF), grant number KP-06N37/29". "Innovative packaging, extending the shelf life of fruits and vegetables by multicomponent edible coatings (ECOATFRUIT)".

\section{Acknowledgments}

The authors thank the Bulgarian Ministry of Education, Youth and Science, a national project for "Young Scientists and Postdoctoral Students" RMS №577 from August 17, 2018.

\section{Conflicts of Interest}

The authors declare no conflict of interest.

\section{References}

1. Chen, H.; Wang, J.; Cheng, Y.; Wang, C.; Liu, H.; Bian, H.; Han, W. Application of protein-based films and coatings for food packaging: A review. Polymers 2019, 11, 2039, https://doi.org/10.3390/polym11122039.

2. Thakur, R.; Pristijono, P.; Scarlett, C.J.; Bowyer, M.; Singh, S.P.; Vuong, Q.V. Starch-based films: Major factors affecting their properties. Int. J. Biol. Macromol. 2019, 132, 1079-1089, https://doi.org/10.1016/j.ijbiomac.2019.03.190.

3. Al-Hashimi, AG.; Ammar, AB; Cacciola, F; Lakhssassi, N. Development of a Millet Starch Edible Film Containing Clove Essential Oil. Foods. 2020, 9, 184, https://doi.org/10.3390/foods9020184.

4. Vedove, T.M.; Maniglia, B.C.; Tadini, C.C. Production of sustainable smart packaging based on cassava starch and anthocyanin by an extrusion process. J. Food Eng. 2021, 289, 110274, https://doi.org/10.1016/j.jfoodeng.2020.110274. 
5. Rao, J.; Chen, B.; McClements, D. J. Improving the efficacy of essential oils as antimicrobials in foods: Mechanisms of action. Annu Rev Food Sci Technol. 2019, 10, 365-387, https://doi.org/10.1146/annurevfood-032818-121727.

6. Sapper, M.; Talens, P.; Chiralt, A. Improving Functional Properties of Cassava Starch-Based Films by Incorporating Xanthan, Gellan, or Pullulan Gums. Int. J. Polym. Sci. 2019, 2019, 5367164, https://doi.org/10.1155/2019/5367164.

7. Tantala, J.; Rachtanapun, C.; Tongdeesoontorn, W.; Jantanasakulwong, K.; Rachtanapun, P. Moisture sorption isotherms and prediction models of carboxymethyl chitosan films from different sources with various plasticizers. Adv. Mater. Sci. Eng. 2019, 2019, 4082439, https://doi.org/10.1155/2019/4082439.

8. Kamdem, J.P.; Duarte, A.E.; Lima, K.R.R.; Rocha, J.B.T.; Hassan, W.; Barros, L.M.; Tsopmo, A. Research trends in food chemistry: A bibliometric review of its 40 years anniversary (1976-2016). Food Chem. 2019, 294, 448-457, https://doi.org/10.1016/j.foodchem.2019.05.021.

9. Sakač, M.B.; Jovanov, P.T.; Marić, A.Z.; Pezo, L.L.; Kevrešan, Ž.S.; Novaković, A.R.; Nedeljković, N.M. Physicochemical properties and mineral content of honey samples from Vojvodina (Republic of Serbia). Food Chem. 2019, 276, 15-21, https://doi.org/10.1016/j.foodchem.2018.09.149.

10. Wang, B.; Sui, J.; Yu, B.; Yuan, C.; Guo, L.; Abd El-Aty, A. M.; Cui, B. Physicochemical properties and antibacterial activity of corn starch-based films incorporated with Zanthoxylum bungeanum essential oil. Carbohydr. Polym. 2021, 254, 117314, https://doi.org/10.1016/j.carbpol.2020.117314.

11. Ju, J.; Xie, Y.; Guo, Y.; Cheng, Y.; Qian, H.; Yao, W. Application of edible coating with essential oil in food preservation. Crit Rev Food Sci Nutr. 2018, 01-62, https://doi.org/10.1080/10408398.2018.1456402.

12. Ilyas, R.A.; Sapuan, S.M.; Ibrahim, R.; Abral, H.; Ishak, M.R.; Zainudin, E.S.; Jumaidin, R. Effect of sugar palm nanofibrillated cellulose concentrations on morphological, mechanical and physical properties of biodegradable films based on agro-waste sugar palm (Arenga pinnata (Wurmb.) Merr) starch. J. Mater. Res. Technol. 2019, 8, 4819-4830, https://doi.org/10.1016/j.jmrt.2019.08.028.

13. Hasan, M.; Rusman, R.; Khaldun, I.; Ardana, L.; Mudatsir, M.; Fansuri, H. Active edible sugar palm starchchitosan films carrying extra virgin olive oil: Barrier, thermo-mechanical, antioxidant, and antimicrobial properties. International Journal of Biological Macromolecules 2020, 163, 766-775, https://doi.org/10.1016/j.ijbiomac.2020.07.076.

14. do Evangelho, J.A.; da Silva Dannenberg, G.; Biduski, B.; El Halal, S.L.M.; Kringel, D.H.; Gularte, M.A.; da Rosa Zavareze, E. Antibacterial activity, optical, mechanical, and barrier properties of corn starch films containing orange essential oil. Carbohydr. Polym. 2019, $222, \quad$ 114981, https://doi.org/10.1016/j.carbpol.2019.114981.

15. Jung, S.; Cui, Y.; Barnes, M.; Satam, C.; Zhang, S.; Chowdhury, R.A.; Ajayan, P.M. Multifunctional BioNanocomposite Coatings for Perishable Fruits. Adv. Mater. 2020, 32, 1908291, https://doi.org/10.1002/adma.201908291.

16. Fonseca-García, A.; Jiménez-Regalado, E.J.; Aguirre-Loredo, R.Y. Preparation of a novel biodegradable packaging film based on corn starch-chitosan and poloxamers. Carbohydr. Polym. 2021, 251, 117009, https://doi.org/10.1016/j.carbpol.2020.117009.

17. Liu, Z.; Lin, D.; Shen, R.; Zhang, R.; Liu, L.; Yang, X. Konjac glucomannan-based edible films loaded with thyme essential oil: Physical properties and antioxidant-antibacterial activities. Food Packag. and Shelf Life 2021, 29, 100700, https://doi.org/10.1016/j.fpsl.2021.100700.

18. Restrepo, A.E.; Rojas, J.D.; García, O.R.; Sánchez, L.T.; Pinzón, M.I.; Villa, C.C. Mechanical, barrier, and color properties of banana starch edible films incorporated with nanoemulsions of lemongrass (Cymbopogon citratus) and rosemary (Rosmarinus officinalis) essential oils. Food Sci. Technol. Int. 2018, 24, 705-712. https://doi.org/10.1177/1082013218792133.

19. Hashim, R.H.R.; Gunny, A.A.N.; Sam, S.T.; Kamaludin, N.H.I.; Shamsuddin, M.R. Effects of incorporation of essential oil into film for fruit packaging application. IOP Conf. Ser. Earth and Environ. Sci. 2021, 765, 012020, https://doi.org/10.1088/1755-1315/765/1/012020.

20. Nešić, A.; Cabrera-Barjas, G.; Dimitrijević-Branković, S.; Davidović, S.; Radovanović, N.; Delattre, C. Prospect of polysaccharide-based materials as advanced food packaging. Molecules 2020, 25, 135, https://doi.org/10.3390/molecules25010135.

21. Mohamed, S.A.; El-Sakhawy, M.; El-Sakhawy, M.A.M. Polysaccharides, protein and lipid-based natural edible films in food packaging: A review. Carbohydr. Polym. 2020, 238, 116178, https://doi.org/10.1016/j.carbpol.2020.116178.

22. Socaciu, M.-I.; Fogarasi, M.; Semeniuc, C.A.; Socaci, S.A.; Rotar, M.A.; Mureşan, V.; Pop, O.L.; Vodnar, D.C. Formulation and Characterization of Antimicrobial Edible Films Based on Whey Protein Isolate and Tarragon Essential Oil. Polymers 2020, 12, 1748, https://doi.org/10.3390/polym12081748.

23. Díaz-Montes, E.; Castro-Muñoz, R. Edible Films and Coatings as Food-Quality Preservers: an Overview. Foods 2021, 10, 249, https://dx.doi.org/10.3390/foods10020249. 
24. dos Santos, B.M.M.; Pizato, S.; Cortez-Vega, W.R. Natural edible films and coatings applied in food: a bibliographic review. Research, Society and Development 2020, 9, e578997613-e578997613, https://doi.org/10.33448/rsd-v9i9.7613.

25. Valizadeh, S.; Naseri, M.; Babaei, S.; Hosseini, S.M.H.; Imani, A. Development of bioactive composite films from chitosan and carboxymethyl cellulose using glutaraldehyde, cinnamon essential oil and oleic acid. Int. J. Biol. Macromol. 2019, 134, 604-612, https://doi.org/10.1016/j.ijbiomac.2019.05.071.

26. Gonçalves, I.; Lopes, J.; Barra, A.; Hernández, D.; Nunes, C.; Kapusniak, K.; Coimbra, M.A. Tailoring the surface properties and flexibility of starch-based films using oil and waxes recovered from potato chips byproducts. Int. J. of Biol. Macromol. 2020, 163, 251-259, https://doi.org/10.1016/j.ijbiomac.2020.06.231.

27. Díaz-Galindo, E.P.; Nesic, A.; Bautista-Baños, S.; Dublan García, O.; Cabrera-Barjas, G. Corn-starch-based materials incorporated with cinnamon oil emulsion: Physico-chemical characterization and biological activity. Foods, 2020, 9, 475, https://doi.org/10.3390/foods9040475.

28. Rech, C.R.; Brabes, K.C.; Silva, B.E.; Martines, M.A.; Silveira, T.F.; Alberton, J.; Martelli, S.M. Antimicrobial and Physical-Mechanical Properties of Polyhydroxybutyrate Edible Films Containing Essential Oil Mixtures. J. Polym. Environ. 2021, 29, 1202-1211, https://doi.org/10.1007/s10924-020-019430 . 